Article

\title{
Feasibility of Developing Sustainable Concrete Using Environmentally Friendly Coarse Aggregate
}

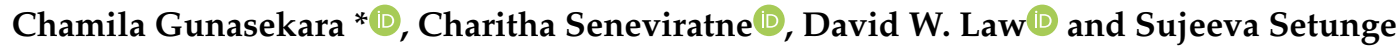 \\ School of Engineering, RMIT University, Melbourne 3000, Victoria, Australia; \\ s3737789@student.rmit.edu.au (C.S.); david.law@rmit.edu.au (D.W.L.); sujeeva.setunge@rmit.edu.au (S.S.) \\ * Correspondence: chamila.gunasekara@rmit.edu.au; Tel.: +61-3-9925-1709; Fax: +61-3-9639-0138
}

Received: 6 July 2020; Accepted: 26 July 2020; Published: 28 July 2020

\begin{abstract}
Quarry aggregate reserves are depleting rapidly within Australia and the rest of the world due to an increasing demand for aggregates driven by expansion in construction. The annual production of premix concrete in Australia is approximately 30 million cubic meters, while $3-5 \%$ of concrete delivered to site remains unused and is disposed of in landfill or crushing plants. The production of coarse aggregates using this waste concrete is potentially a sustainable approach to reduce environmental and economic impact. A testing program has been conducted to investigate mechanical performance and permeation characteristics of concrete produced using a novel manufactured coarse aggregate recycled directly from fresh premix concrete. The recycled coarse aggregate (RCA) concrete satisfied the specified 28-day design strength of $25 \mathrm{MPa}$ and $40 \mathrm{MPa}$ at 28 days and a mean compressive strength of $60 \mathrm{MPa}$ at 90 days. Aggregate grading was observed to determine strength development, while low water absorption, low drying shrinkage, and higher packing density indicate that the RCA concrete is a high-quality material with a dense pore structure. The rough fracture surface of the aggregate increased the bond between C-S-H gel matrix and RCA at the interfacial transition zone. Furthermore, a good correlation was observed between compressive strength and all other mechanical properties displayed by the quarried aggregate concrete. The application of design equations as stated in Australian standards were observed to provide a conservative design for RCA concrete structures based on the mechanical properties.
\end{abstract}

Keywords: aggregate demand; waste concrete; sustainability; mechanical properties; microstructure

\section{Introduction}

Concrete continues to be one of the most dominant materials in modern day construction activities. Concrete has many versatile uses such as being adaptable, mouldable, and freely available in the market and affordable. Regrettably, despite all of these benefits concrete has an adverse effect on the environment $[1,2]$. Around $65-75 \%$ of the volume of concrete is occupied by aggregates, where $35-45 \%$ of the volume of is taken up by coarse aggregates and the rest is occupied by fine aggregates [3]. More than 10 billion tonnes of concrete is produced annually worldwide [4]. Australia alone produces around 30 million cubic meters of concrete annually, consuming about 130 million tonnes of aggregates [5,6]. It has been predicted that in order to satisfy the demand for new infrastructure due to the rising population demand Australia will need to produce around 210 million tonnes of coarse aggregates by 2050 , which is a $60 \%$ increase in production [5].

It is noted that the concrete construction industry contributes to $\mathrm{CO}_{2}$ emissions worldwide. Global cement production contributes $5-7 \%$ to anthropogenic $\mathrm{CO}_{2}$ emissions [7,8], emitting $0.66-0.8$ tonnes of $\mathrm{CO}_{2}$ from 1 tonne of cement production [9-12]. In addition, the process energy usage and greenhouse gas emissions from natural crushed aggregate is around 7.4 to $8.0 \mathrm{~kg}$ of equivalent $\mathrm{CO}_{2}$ emission per tonne. The emissions from trucks and dumpers, as well as use of crushers which result in considerable 
dust and particulate emissions, increase global warming [13-15]. The concrete production process generates a high demand for aggregates which will inevitably lead to a sparsity of resources as demand increases. Quarrying for aggregates involves the removal of rock which can impact the natural drainage patterns, stability of slopes, and the aesthetic value of the environment. This may involve the removal of trees by means of blasting which both directly impacts global warming and the local fauna. Further, naturally crushed aggregates can also contain crystalline silica or free silica which is created and released during production and handling which can pose serious health problems. Hence, finding alternative aggregate sources is essential for the construction industries.

The practice of recycling concrete demolition waste, which has been widely adopted, is an excellent source of recycled coarse aggregate for new concrete production. In the last few decades, there has been a progression in the utilization of recycled coarse aggregates, derived from construction and demolition waste, for concrete production in many developed countries [16]. However, developing countries lag behind in the use of recycle aggregate in construction [16], as illustrated by the recovery percentage of construction and demolition waste in Japan, UK and Australia, USA, China, Thailand and South Africa are $80 \%$ [17], 65\% [18], 62\% [19], 48\% [20], 40\% [21], 32\% [22], and 16\% [23], respectively. Furthermore, there are numerous recent advancements on techniques of producing recycled aggregates and techniques of utilization [24]. In USA, the majority of the recycled aggregates are being used in road base construction followed by bitumen concrete [16]. In Europe, the majority of the recycled aggregates are utilized in building construction followed by utilization in roadways and railways [25]. Recycled aggregate produced from construction and demolition waste recycling plants can be classified into two groups: recycled concrete aggregates, (i.e., aggregates from waste concrete crushing) and mixed recycled aggregates (i.e., aggregates from recycling ceramic and concrete waste). Mixed recycled aggregate is produced extensively worldwide compared to recycled concrete aggregates. It has been established that concrete made using recycled coarse aggregate can be compared with traditional concrete [26]. However, the negative effect of recycled aggregates on the mechanical properties of concrete is higher when using mixed recycled aggregates than when using recycled coarse aggregate [27]. Replacing $50 \%$ of natural aggregate by mixed recycled aggregates produces a decrease in compressive strength up to $20 \%$ [28-30] whereas $100 \%$ mixed recycled aggregates replacement produces a decrease in compressive strength up to $45 \%$ [30-32]. However, replacing coarse aggregates up to $30 \%$ with recycled concrete aggregates have marginal effect on compressive strength development [33]. Further, even with $100 \%$ of coarse recycled concrete aggregate replacement, the compressive strength reduction is only 20 to $30 \%$ [34,35]. The reduction percentage of compressive strength depends on the quality of recycled aggregate used [36,37]. Recycle aggregate concrete has shown comparable long term strength development to normal aggregate concrete $[33,38]$.

A possible alternative source of the recycled coarse aggregate is that of the waste concrete that is unused in construction projects. At present this is discharged from the mixer, allowed to set and then crushed to produce recycled coarse aggregate. This process requires both time and energy in detouring to discharge the unused concrete, the setting time and then the crushing and grading. An alternative approach has been developed which directly treats the wet mix. Using a patented hygroscopic chemical formula, a powder is added to the wet concrete. Due to the hygroscopic property it absorbs virtually all of the water and moisture in the mix. Once the mix is dry it allows the fine and the coarse aggregate to be separated and stored for later use. This process does not require the concrete to harden as in most concrete recycling techniques, and therefore significantly reduces the time needed in traditional concrete recycling. In addition, the procedure does not require heavy machinery to crush any concrete, nor does it require transportation to storage sites, hence conserving energy and fossil fuel usage. Furthermore, due to the highly hygroscopic nature of the powder, when used in sufficient amounts it will absorb the majority of the water and moisture in the mixer, leaving the interior almost dry with no sticky residue, this makes it significantly easier to clean the trucks potentially using only one tenth of the usual amount of water to clean the mixing equipment compared to a mixer used for traditional concrete. Ferrari et al. [39] used a similar approach to produce recycled aggregate from fresh concrete 
waste without employing mechanical crushing. The authors [39] used a superabsorbent polymer and an ettringite forming compound to produce the recycled aggregates. This recycled aggregate was used in concrete, with up to $30 \%$ replacement of the natural aggregates. However, this technique is significantly different from the other fresh concrete waste recycling techniques commonly reported in the literature [40-42].

In this study a novel methodology to reclaim unused aggregate from wet mix concrete was employed to produce recycled coarse aggregate. An investigation was undertaken to determine the effect of replacing standard quarried coarse aggregate with the recycled concrete aggregate while maintaining a similar aggregate grading. Two different standard concrete design strengths, i.e., $25 \mathrm{MPa}$ and $40 \mathrm{MPa}$, corresponding to Australian concrete code AS 3600 [43] were employed to produce recycled coarse aggregates. This paper presents the key engineering properties, such as compressive strength, flexural strength, splitting tensile strength, elastic modulus, water absorption and drying shrinkage of concrete produced. The observed test results up to 90 days of age are reported, and the variations in properties observed are then explained in conjunction with the microstructure development.

\section{Research Significance}

To date, much of the research on recycled aggregate concrete had focused on utilising coarse aggregate from construction and demolition waste. However, only very few studies have focused on extracting aggregate from fresh wet concrete. This study investigates the performance of concrete utilising patented [44] manufactured coarse aggregate recycled directly from excess fresh waste concrete produced in batching plants or construction yards. Utilising this manufactured aggregate in concrete production could reduce the demand for quarried aggregate as well as utilizing a waste product from concrete production, minimizing the environmental impact. Hence, the research can be highly beneficial in identifying the possible application of manufactured coarse aggregate and the associated engineering performance. The material could be a commercially viable and sustainable alternative to the current aggregates used in the construction industry.

\section{Experimental Procedure}

\subsection{Materials and Mix Design}

ASTM Type 1 Portland cement (PC) was used as cementitious material for the production of recycled coarse aggregate (RCA) and basalt quarried aggregate concretes [45]. Table 1 shows chemical composition of which is derived using X-ray fluorescence. The adopted mix proportions based on absolute volume method are reported in Table 2 . Two concretes mix designs were investigated with the targeted compressive strength of $25 \mathrm{MPa}$ and $40 \mathrm{MPa}$ at 28 days. The fine aggregates were used in the form of uncrushed river sand with a fineness modulus of 2.7 and specific gravity of 2.5 . The aggregates were oven dried for over $24 \mathrm{~h}$ prior to using to control the water content within batches. The properties of RCA and Basalt (quarried) coarse aggregate were tested in accordance with relevant standards, and results are summarised in Table 3. The RCA- 25 and RCA- 40 represent aggregates produced by recycling fresh returned concrete with Grade 25 and Grade 40, respectively. The RCA-25 has higher water absorption $(6.85 \%)$ and moisture content $(4.3 \%)$ than Basalt coarse aggregate (water absorption of $1.45 \%$ and moisture content of $0.85 \%$ ). The coarse aggregates were used in saturated surface dry conditions to control the water absorption from cement paste. In both concretes, total aggregates content was fixed $65 \%$ by volume, and other mix ingredients were adjusted to keep the same material volume and water/cement ratio. The workability of all concrete mixes was kept at $80-100 \mathrm{~mm}$ range by adjusting the superplasticizer content, Table 2. Demineralized water was used throughout. 
Table 1. Chemical composition of Portland cement (PC).

\begin{tabular}{ccccccccccccc}
\hline \multirow{2}{*}{ Material } & \multicolumn{10}{c}{ By Weight (\%) } \\
\cline { 2 - 11 } & $\mathrm{SiO}_{2}$ & $\mathrm{Al}_{2} \mathrm{O}_{3}$ & $\mathrm{Fe}_{2} \mathrm{O}_{3}$ & $\mathbf{C a O}$ & $\mathbf{P}_{2} \mathbf{O}_{5}$ & $\mathrm{TiO}_{2}$ & $\mathbf{M g O}$ & $\mathbf{K}_{2} \mathbf{O}$ & $\mathbf{S O}_{3}$ & $\mathbf{M n O}$ & $\mathbf{N a}_{2} \mathbf{O}$ & ${ }^{*}$ LOI \\
\hline Cement & 22.5 & 4.5 & 0.4 & 66.3 & 0.67 & 0.20 & 0.51 & 0.15 & 2.8 & 0.10 & 0.17 & 1.7 \\
\hline \multicolumn{10}{c}{ Loss on ignition (unburnt carbon content). } & 17
\end{tabular}

Table 2. Mix proportions used in concrete $\left(\mathrm{kg} / \mathrm{m}^{3}\right)$.

\begin{tabular}{|c|c|c|c|c|c|c|c|c|}
\hline $\begin{array}{l}\text { Concrete } \\
\text { Type }\end{array}$ & $\begin{array}{c}\text { Design } \\
\text { Strength }\end{array}$ & $\begin{array}{c}\text { Mix } \\
\text { Notation }\end{array}$ & $\begin{array}{c}\text { Cement } \\
(\mathrm{kg})\end{array}$ & $\begin{array}{l}\text { Sand } \\
(\mathrm{kg})\end{array}$ & $\underset{(\mathrm{kg})}{\text { Aggregate }}$ & $\begin{array}{l}\text { Water } \\
\text { (kg) }\end{array}$ & $\begin{array}{l}\text { Water/Cement } \\
\text { Ratio }\end{array}$ & Superplasticizer \\
\hline BCA & $25 \mathrm{MPa}$ & BCA-25 & 300 & 910 & 1015 & 150 & 0.5 & 2.7 \\
\hline concrete & $40 \mathrm{MPa}$ & BCA-40 & 400 & 800 & 1015 & 160 & 0.4 & 3.6 \\
\hline RCA & $25 \mathrm{MPa}$ & RCA-25 & 300 & 910 & 843 & 150 & 0.5 & 3.6 \\
\hline Concrete & $40 \mathrm{MPa}$ & RCA-40 & 400 & 800 & 843 & 160 & 0.4 & 4.8 \\
\hline $\begin{array}{c}\text { Combined } \\
\text { RCA }\end{array}$ & $25 \mathrm{MPa}$ & $\begin{array}{c}\text { Combined } \\
\text { RCA-25 }\end{array}$ & 300 & 910 & 895 & 150 & 0.5 & 3.3 \\
\hline Concrete & $40 \mathrm{MPa}$ & $\begin{array}{l}\text { Combined } \\
\text { RCA-40 }\end{array}$ & 400 & 800 & 860 & 160 & 0.4 & 4.4 \\
\hline
\end{tabular}

Table 3. Properties of coarse aggregates.

\begin{tabular}{ccccc}
\hline Aggregate Property & RCA-25 & RCA-40 & Basalt Aggregate & Standard \\
\hline Aggregate crushing value & $35.5 \%$ & $30.4 \%$ & $21.2 \%$ & AS 1141.21 [46] \\
Aggregate impact value & $36.1 \%$ & $31.2 \%$ & $21.6 \%$ & VicRoads-RC 371.03 [47] \\
Los Angeles abrasion value & $22.4 \%$ & $25.7 \%$ & $32.7 \%$ & AS 1141.23 [48] \\
Oven dry density & $2250 \mathrm{~kg} / \mathrm{m}^{3}$ & $2250 \mathrm{~kg} / \mathrm{m}^{3}$ & $2650 \mathrm{~kg} / \mathrm{m}^{3}$ & AS 1141.4 [49] \\
Water absorption & $6.85 \%$ & $6.55 \%$ & $1.45 \%$ & ASTM C127 [50] \\
Moisture content & $4.30 \%$ & $4.15 \%$ & $0.85 \%$ & VicRoads-RC 253.01 [51] \\
\hline
\end{tabular}

\subsection{Mixing, Casting, and Curing of Concrete}

Dry materials (i.e., cement, sand, and coarse aggregates) were added to the $120 \mathrm{~L}$ pan type mixer and mixed for $4 \mathrm{~min}$. Once the dry materials are mixed adequately, water was added to the pan mixer and mixed for another 6 min until a homogeneous mix was obtained. A standard slump test was performed to measure the workability of the concrete in accordance with AS 1012.3.1 [52]. The mix was poured into steel moulds in two approximate layers while providing mechanical vibration for each layer using a vibratory table to remove air bubbles and to attain a smooth and glossy finish. Test specimens comprised $100(\phi) \times 200(\mathrm{~h}) \mathrm{mm}^{3}$ cylindrical specimens for density [53], compressive strength [54], elastic modulus [55] and Poisson's ratio [55] tests, $100(\phi) \times 50(\mathrm{~h}) \mathrm{mm}^{3}$ cylindrical specimens for water absorption tests [56], $100 \times 100 \times 350 \mathrm{~mm}^{3}$ beams for flexural strength [57] and $75 \times 75 \times 280 \mathrm{~mm}^{3}$ prisms for drying shrinkage [58]. The steel moulds were kept at $24 \pm 2{ }^{\circ} \mathrm{C}$ of temperature and $70 \%$ relative humidity for $24 \mathrm{~h}$ to provide initial curing to the specimens. After the initial curing period, the specimens were stripped from the moulds and kept in lime saturated water (i.e., to reduce calcium hydroxide leaching from concrete specimens) at room temperature $\left(24 \pm 2{ }^{\circ} \mathrm{C}\right)$ to provide moist curing in accordance with AS 1012.8 [59].

\subsection{Testing}

The compressive strength test was conducted in accordance with AS 1012.9 [54] using MTS compression testing machine by applying a load of $20 \mathrm{MPa} / \mathrm{min}$. Four specimens tested for each data point. Modulus of elasticity and Poisson's ratio were obtained using Technotest compression testing machine coupled with compressometer and extensometer at a constant loading rate of $0.25 \mathrm{MPa} / \mathrm{sec}$ in accordance with AS 1012.17 [55]. AS 1012.12.2 standard [53] was used to identify the reported dry densities. The four point bending flexural strength test was conducted using MTS compression testing machine by applying a load of $1 \mathrm{MPa} / \mathrm{min}$ with respect to AS 1012.11 [57]. The splitting tensile strength test was conducted in accordance with AS 1012.10 by applying a loading rate of $1.5 \mathrm{MPa} / \mathrm{min}$. The water absorption and apparent volume of permeable void (AVPV) percentage is measured in 
accordance with AS 1012.21 standard [56]. The $100 \times 200 \mathrm{~mm}^{3}$ cylindrical moulds were cut into four equal slices and tested according to the standard. The drying shrinkage test was performed in accordance with AS 1012.13 [58]. The drying shrinkage tests were initiated immediately after the 7 days of water curing and continued until 90 days. All shrinkage specimens were kept in a humidity chamber with a temperature of $23 \pm 2{ }^{\circ} \mathrm{C}$ and $50 \%$ relative humidity throughout the testing period. A portable ultrasonic non-destructive tester with a $54 \mathrm{kHz}$ transducer was used to measure the Ultrasonic Pulse Velocity (UPV) in accordance with ASTM C597 [60]. Readings from two directions were observed in each specimen before averaging to get the final UPV value. Scanning Electron Microscope (SEM) images of the concrete microstructure were obtained from a Quanta 200 SEM by using the backscattered electron imaging mode. Images were taken at $10 \mathrm{~mm}$ working distance with $15 \mathrm{eV}$ of energy. The specimens used for the SEM imaging were obtained from concrete specimens by cutting using a diamond saw. SEM samples having dimensions of $10 \mathrm{~mm} \times 5 \mathrm{~mm} \times 5 \mathrm{~mm}$ were prepared using a semiautomatic grinding and polishing machine to produce an even and smooth surface by applying mechanical abrasion up to $3 \mu \mathrm{m}$. Samples were kept in a dehumidifier for a period of $24 \mathrm{~h}$ prior to applying a carbon coat and mounted with conductive, double-sided carbon tape.

\section{Results and Discussion}

\subsection{Aggregate Gradation}

The void content within the aggregate structure is determined by coarse aggregate gradation. The cement paste is required to fill void space in order to obtain the adequate workability for concrete. In addition, the coarse aggregate gradation decreases bleeding, plastic shrinkage cracking, and aggregate segregation. In particular, concrete containing coarse aggregate with poor gradation would increase the segregation in the plastic state before hardening. When there is a loss of moisture from the concrete due to surface evaporation and/or internal consumption at cement hydration, the filled cement paste in void space between the aggregate tends to shrink. Hence, in order to attain the maximum particle interlock and solid volume density in concrete, effective coarse aggregate grading is required.

In this study, a sieve analysis test was conducted for RCA and Basalt coarse aggregate in order to determine the particle size distribution, Figure 1. The grading curves obtained for both coarse aggregates were matched, and the size and quantity of the Basalt aggregate to be used in the RCA was determined accordingly. This provided a similar grading curve for the combined RCA. This means, the combined RCA-25 (i.e., RCA made with 25 MPa concrete) contains $72 \%$ of RCA and $28 \%$ of Basalt aggregates by volume, and combined RCA- 40 (i.e., RCA made with $40 \mathrm{MPa}$ concrete) contains $91 \%$ of RCA and $9 \%$ of Basalt aggregate. The compressive strength of the three concretes produced with specific coarse aggregate is illustrated in Table 4. Basalt aggregate concrete obtained $26.47 \mathrm{MPa}$ and $42.15 \mathrm{MPa}$ compressive strength at 28 days, which satisfied the design strength of $25 \mathrm{MPa}$ and $40 \mathrm{MPa}$, respectively. Both RCA-25 and RCA-40 concretes achieved lower compressive strength at 28 days and did not achieve their design strength. However, combined RCA- 25 and combined RCA- 40 concretes achieved the required design strength at 28 days, Table 4 . This demonstrates that aggregate grading plays a vital role in the compressive strength determination of RCA concrete. Thus, both combined RCA- 25 and combined RCA- 40 concretes were used to prepare concrete specimens for testing mechanical properties. 


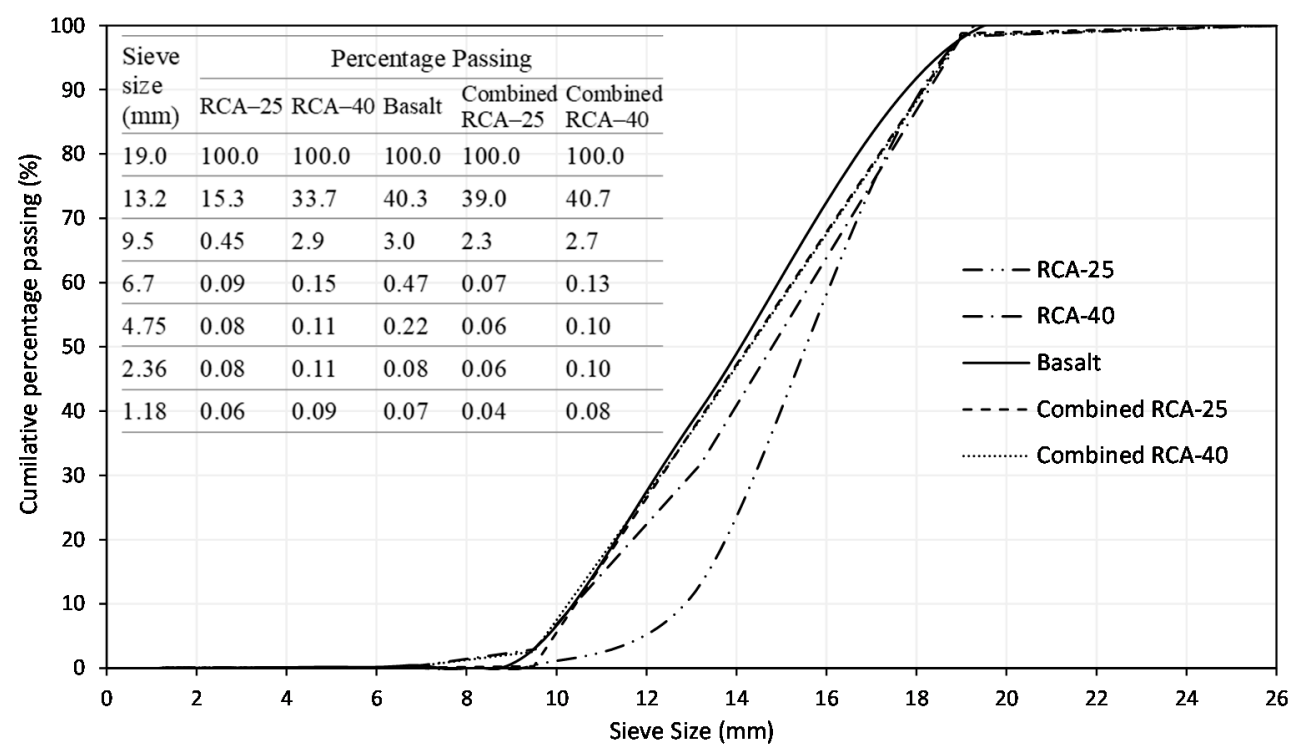

Figure 1. Aggregate grading curve for recycled coarse aggregate (RCA) and Basalt coarse aggregates.

Table 4. Compressive strength of concrete with aggregate grading.

\begin{tabular}{ccccc}
\hline \multirow{2}{*}{ Concrete Type } & Design Strength & Mix Notation & \multicolumn{2}{c}{ Compressive Strength (MPa) } \\
\cline { 3 - 5 } & & & 7-day & 28-day \\
\hline \multirow{2}{*}{ BCA concrete } & $25 \mathrm{MPa}$ & BCA-25 & $19.15 \pm 2.06$ & $26.47 \pm 1.27$ \\
& $40 \mathrm{MPa}$ & BCA-40 & $32.49 \pm 2.92$ & $42.15 \pm 1.14$ \\
\hline \multirow{2}{*}{ RCA Concrete } & $25 \mathrm{MPa}$ & RCA-25 & $15.07 \pm 0.76$ & $19.50 \pm 1.83$ \\
& $40 \mathrm{MPa}$ & RCA-40 & $27.34 \pm 1.95$ & $32.28 \pm 2.06$ \\
\hline Combined RCA & $25 \mathrm{MPa}$ & Combined RCA-25 & $18.40 \pm 0.86$ & $25.85 \pm 0.45$ \\
Concrete & $40 \mathrm{MPa}$ & Combined RCA-40 & $34.07 \pm 1.30$ & $41.10 \pm 1.75$ \\
\hline
\end{tabular}

\subsection{Mechanical Properties}

The compressive strength and dry density variation of combined RCA concrete between 7 and 90 days are shown in Figure 2. The observed 28-day compressive strength of combined RCA concrete made with the two different mixes are identical (Refer Table 4 and Figure 2). The strengths varied between 25.85-24.89 MPa for Combined RCA-25 and 41.10-43.41 MPa for Combined RCA-40. This shows that combined RCA concrete can repeatedly produce similar compressive strength in repeated mixes. Combined RCA-25 and RCA-40 concretes displayed a compressive strength development over time, ranging from 19.29 to $44.50 \mathrm{MPa}$ and 36.35 to $60.70 \mathrm{MPa}$ between 7 and 90 days, respectively. During this period, the combined RCA- 25 and combined RCA- 40 concretes achieved $130.7 \%$ and $81.8 \%$ strength development, respectively. In literature, the performance of most other concretes with RCA has shown a $20 \%$ to $30 \%$ reduction in compressive strength in comparison to corresponding natural aggregate concrete $[33,61]$. However, the compressive strengths obtained from the combined RAC in this study demonstrated no significant difference in the strengths achieved. Furthermore, Ferrari et al. [39] also observed no reduction in compressive strength when using a similar RAC produced using returned concrete, though this contained only $30 \%$ replacement of coarse aggregates. The compressive strength of combined RCA- 25 and combined RCA-40 concretes are in well excess of the specified lowest strength noted Australian Standards, AS 3600 [62] for exposure category A1 (20 MPa), A2 (25 MPa), B1 (32 MPa), and B2 (40 MPa) at 28 days. Hence, combined RCA-25 concrete could be used for residential structures in non-aggressive soil and non-industrial near coastal structures while combined RCA-40 concrete can be applied in industrial buildings and coastal structures. 

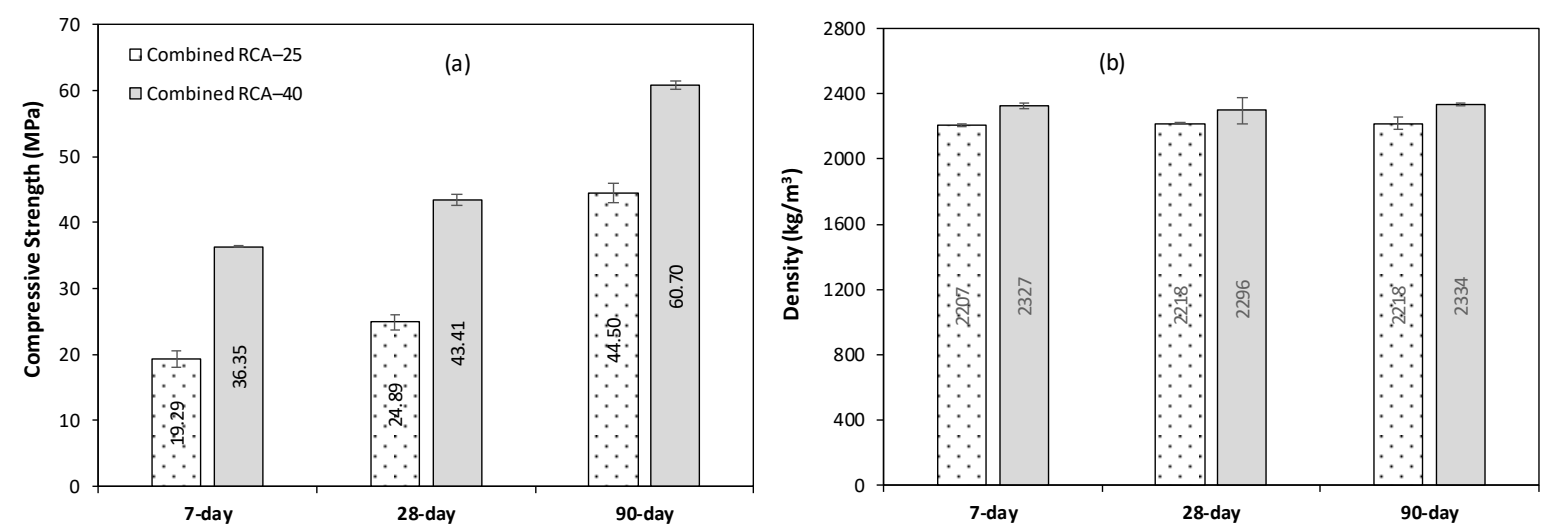

Figure 2. (a) Compressive strength and (b) density development of combined RCA concrete.

While RCA has higher water absorption and moisture content than Basalt aggregates, both were used in saturated surface dry condition. This prevented extra water loss from the concrete mix due to absorption by the coarse aggregates. In compressive strength testing, both Basalt aggregate and combined RCA concretes displayed cylindrical cone failure [3]. Considering the Basalt aggregate concrete, the fracture plane passed mainly around the aggregates, but in the combined RCA concrete, it passed mainly through the RCA aggregates. It is speculated that the cause of the fracture through the RCA aggregates is due to lower strength of the coarse aggregates compared with cement paste. It was observed that the crushing value of RCA-25 and RCA-40 coarse aggregates are $35.9 \%$ and $30.4 \%$, respectively, which are significantly higher than Basalt coarse aggregate $(21.2 \%$ crushing value). The higher the aggregate crushing value will lower the strength of coarse aggregate. Hence, the examined fracture behaviour proves that RCA's strength is the governing factor for the final compressive strength of combined RCA concrete. On the other hand, the dry density of combined RCA concrete increased with time, increasing from 2207 and $2334 \mathrm{~kg} / \mathrm{m}^{3}$ between 7 to 90 days, Figure $2 \mathrm{~b}$. Both concretes displayed $5-10 \%$ lower density compared to quarried aggregate concrete which is characteristically cited as $2400 \mathrm{~kg} / \mathrm{m}^{3}$ [62]. The efficiency factor (i.e., compressive strength/mass ratio) of Combined RCA-25 and Combined RCA-40 concretes at 28 days are 11,655 and 17,901 Nm/kg. In comparison, BCA-25 and BCA-40 concretes have an efficiency factor of 11,029 and 17,563 Nm/kg at 28 days. Given the high efficiency factor, Combined RCA concretes could provide more utility space and architectural freedom in building construction.

Tensile strength development of combined RCA concrete is presented in Figure 3. The flexural strength of the combined RCA-25 and RCA-40 concretes increased from 3.35-3.73 and 3.46-4.55 MPa between 7 to 90 days, respectively. Flexural strength generally determines the failure tensile stress of a concrete beam without steel reinforcement. The flexural strength increased with time and was approximately $14.7 \%$ and $9.1 \%$ of the respective compressive strength of combined RCA- 25 and RCA- 40 concretes. It was noted that the flexural strength/compressive strength ratio of combined RCA-25 concrete is slightly higher than the typical range of $9-12 \%$ cited for quarried aggregate concrete. Moreover, the splitting tensile strength of all combined RCA concretes increased with time. This ranged from 2.03 to $3.15 \mathrm{MPa}$ for combined RCA-25 and 3.04 to $4.07 \mathrm{MPa}$ for combined RCA-40 between 7 and 90 days and varied from 8 to $12 \%$ of the respective compressive strength. According to the AS 3600 [62], Equations (1) and (2), can be used to estimate the flexural and splitting tensile strengths as a function of compressive strength. The estimated flexural strength of combined RCA-25 and RCA-40 are 2.64, 2.99, 4.00 MPa and 3.62, 3.95, 4.67 MPa, respectively, at 7, 28, 90 days. Furthermore, the estimated splitting tensile strength of combined RCA-25 and RCA-40 are 1.76, 2.00, 2.67 MPa and 2.41, 2.64, 3.12 MPa, respectively, at 7, 28, 90 days. The experimental results of both combined RCA concretes showed close resemblance with the estimated flexural strength, whereas the experimental splitting tensile strength was marginally higher than the predicted tensile strength for quarried aggregate concrete. 


$$
\begin{aligned}
& f_{c t . f}^{\prime}=0.6 \sqrt{f_{c}^{\prime}} \mathrm{MPa} \\
& f_{c t . s p}^{\prime}=0.4 \sqrt{f_{c}^{\prime}} \mathrm{MPa}
\end{aligned}
$$

where $f_{c t . f}^{\prime} f_{c t . s p}^{\prime}$ and $f_{c}^{\prime}$ are characteristic flexural, splitting tensile, and compressive strength, respectively.

In both combined RCA concretes, the observed flexural strength is higher than the splitting tensile strength, Figure 3. This is similar to the PC concrete produced with quarried aggregates [3]. In PC concrete, the flexural tensile strength overestimates the actual tensile strength [3]. Literature has reported that actual tensile strength of concrete is about $75 \%$ of the measured flexural strength [63]. This is primarily due to loading arrangement on the tensile stress distribution for two different test procedures. The splitting tensile test generates biaxial stress distribution, as a result, the larger volume of the specimen is exposed to tensile stress and the remaining volume is subjected to horizontal compressive stress. However, in the flexural strength test, the maximum fibre stress is at the bottom fibre which is higher than the splitting test. This is due to propagation of crack at flexure loading, which is blocked by lower stressed material near to the neutral axis. Hence, available energy is less than that required to form new crack surfaces, which results in a higher tensile failure resistance.
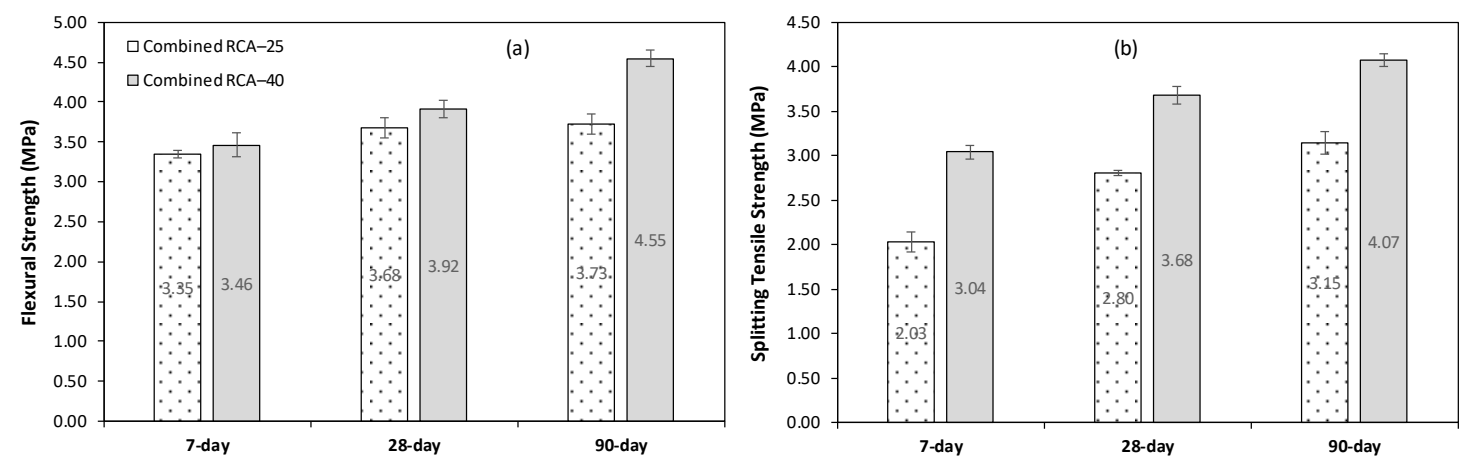

Figure 3. (a) Flexural strength and (b) Splitting tensile strength development of Combined RCA concrete.

The required stress to induce unit strain in concrete at elastic limit is denoted as the modulus of elasticity. This impacts the axial shortening and short term vertical deflection of structural members under compression load. The modulus of elasticity in Figure 4 tended to increase with time while following a similar trend observed in compressive and tensile strengths. The elastic modulus ranged from 20,748 to 29,672 MPa for combined RCA-25 and 32,526 to 37,879 MPa for combined RCA-40 concrete between 7 and 90 days. Elastic modulus values have a high variability, thus experimentally observed values are allowed to vary between $\pm 20 \%$ of the calculated value Equations (3) and (4), based on AS 3600 [62]. The predicted elastic modulus for combined RCA-25 and combined RCA-40 are 19,581, 22,409, 29,259 MPa and 29,101, 30,599, 34,615 MPa, respectively, at 7, 28, 90 days. The elastic modulus of the combined RCA concretes is observed to be higher than the prediction provided in AS3600; however, most results fall within the allowed 20\% tolerance limit. Thus, data indicates that the elastic modulus of combined RCA concrete is comparable to that of quarried aggregate concrete of similar compressive strengths.

$$
\begin{gathered}
E_{c}=0.043 p^{1.5} \sqrt{f_{c m i}} \mathrm{MPa} \text {; when } f_{c m i} \leq 40 \mathrm{MPa} \\
E_{c}=\left(0.024 \sqrt{f_{c m i}}+0.12\right) p^{1.5} \mathrm{MPa} \text {; when } f_{c m i}>40 \mathrm{MPa}
\end{gathered}
$$

where $E_{c}, p$, and $f_{c m i}$ are elastic modulus, density, and mean compressive strength, respectively.

The Poisson's ratio of conventional aggregate concrete is usually in the range from $0.11-0.21$, but typically stay in the range from $0.15-0.20$ [64]. The measured Poisson's ratio values of combined RCA-25 and combined RCA-40 concretes at 7, 28 and 90 days are $0.11,0.14,0.15$ and $0.14,0.16,0.17$, 
respectively. All these measured values are within the $0.11-0.21$ range and are comparable to quarried aggregate concrete.

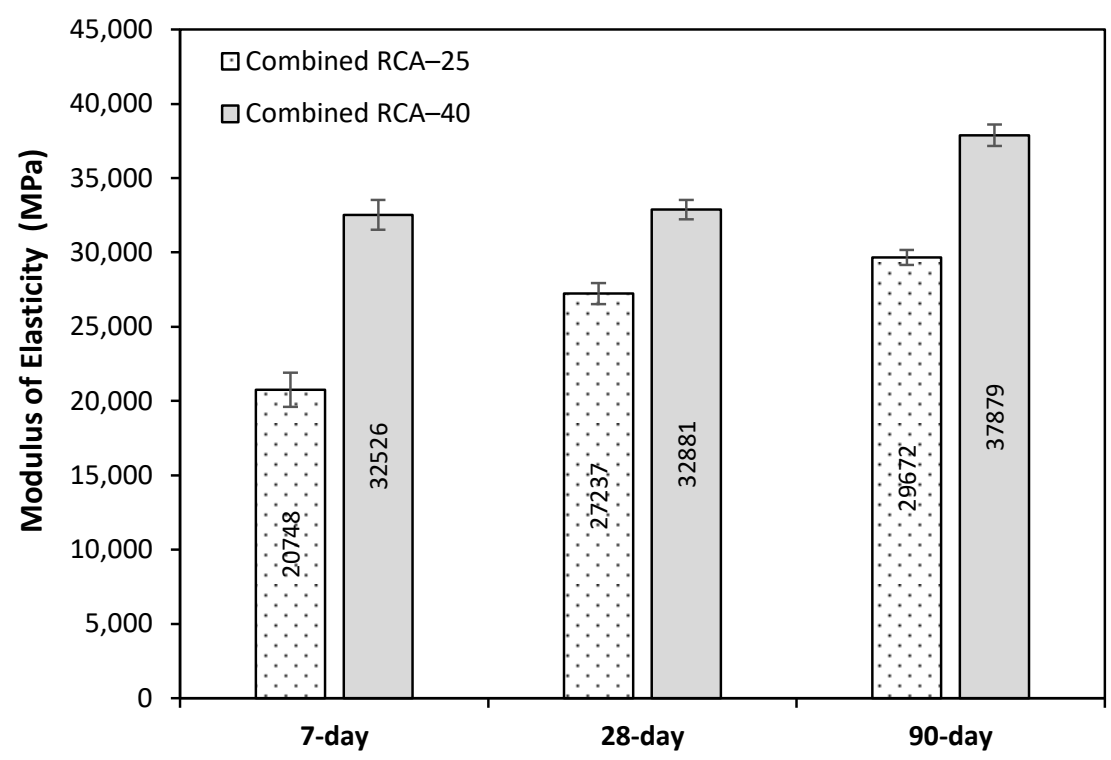

Figure 4. Modulus of Elasticity development of combined RCA concrete.

\subsection{Shrinkage and Permeation Charcteristics}

When concrete is exposed to drying at an early age, shrinkage will occur due to capillary suction and cause micro-cracking. Drying shrinkage is principally dependent on the ambient conditions and the mix proportions. The drying shrinkage of combined RCA concretes is reported in Figure 5 . The observed drying shrinkage of combined RCA concretes at 90 days is 505 microstrain, which is significantly lower than the maximum permitted value of 800 microstrain recommended by AS3600 standard [62] for concrete use in Australia, Figure 5. The majority of the drying shrinkage was observed by the 40th day and continued to increase at a decreasing rate throughout the period. This is similar to the drying shrinkage pattern typically observed in quarried aggregate concrete [3]. In addition, the drying shrinkage pattern is in good agreement with similar literature containing RAC concrete with high replacement percentages [65]. Thus, the use of Combined RCA is more effective in resisting the drying shrinkage of concrete, which in turn can decrease secondary reinforcement quantity requirements and the cost of RCA concrete structures.

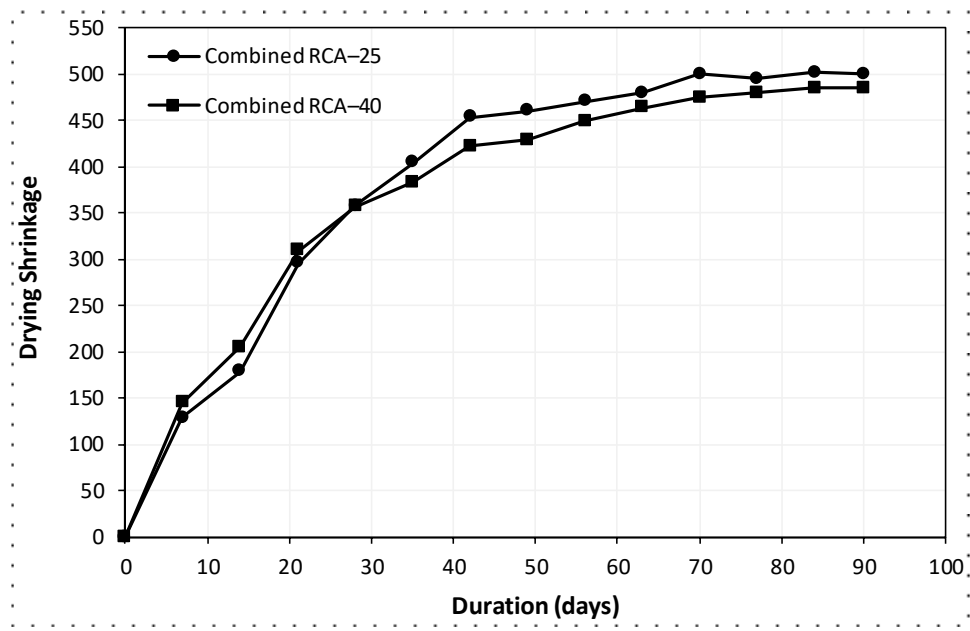

Figure 5. Drying shrinkage of combined RCA concrete. 
The water absorption and apparent volume of permeable voids (AVPV) of combined RCA concretes are shown in Figure 6. The water absorption of the two RCA concretes varied over a considerable range. Both combined RCA concretes displayed about $7 \%$ higher water absorption rate at 7 days, but started to reduce with time, giving approximately $4.5 \%$ and $3.7 \%$ at 28 and 90 days, respectively. When water absorption is greater than 5\% in PC concrete, this is classified as high permeable concrete, while less than $3 \%$ is classified as low permeable concrete [66]. It was noted that combined RCA concretes exceeded this upper limit at early age and behaved as high permeable concrete, which indicates a highly porous external surface with a large number of capillaries and high connectivity within pores. These capillaries initiate water absorption through capillary suction at the concrete surface. However, a significant improvement was observed with the age, and the absorption of combined RCA concrete was below the upper limit after 28 days. It further decreased over time and stayed slightly above the low permeable limit at 90 days. Furthermore, the water absorption of Combined RCA concrete is in good agreement with the other fresh concrete recycled aggregate concretes [40]. Figure $6 \mathrm{~b}$ displays the AVPV of the two combined RCA concretes. The AVPV, or closed porosity, is a percentage of pore space such as capillary pores, gel pores, and air voids within the combined RCA concrete. Similar to water absorption, AVPV of both combined RCA concretes decreased with time. When AVPV is less than $13 \%$, it is classified as good quality concrete, while greater than $18 \%$ is classified as poor quality concrete [67]. Both combined RCA concretes were in 13-18\% at 7 days but reduced to below the lower limit at 28 and 90 days, indicating limited pore interconnectivity in their pore structure.
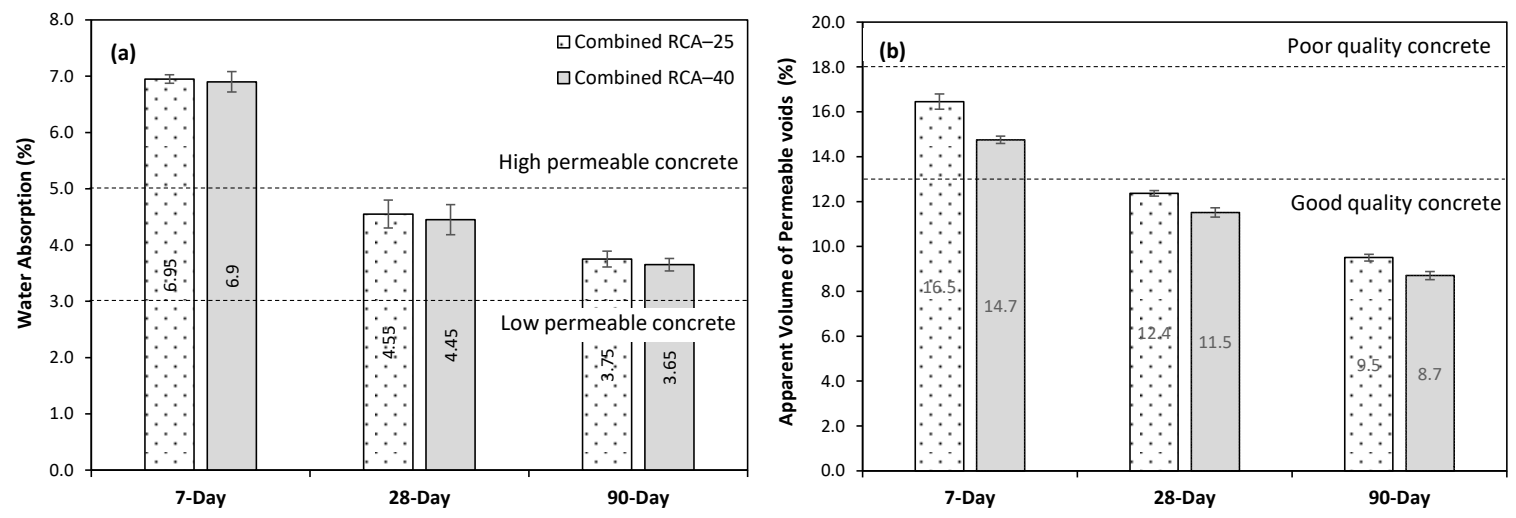

Figure 6. (a) Water absorption and (b) apparent volume of permeable void (AVPV) of combined RCA concrete.

\subsection{Microstructure}

The tensile strength of concrete is strongly influenced by the cement gel-aggregate bond strength [3]. The interfacial transition zone (ITZ) has a different microstructure to the other regions in the cement matrix and is identified as the weakest interface for the generation of early micro-cracking. The ITZ in concrete is produced by the disorder of packing the anhydrous cement grains in the transition zone [68]. Figure 7 shows that RCA had a strong bond with C-S-H gel matrix especially in the ITZ. Both combined RCA concretes had a small number of microcracks in ITZ region at 7 days, however, these cracks filled with C-S-H gel due to ongoing hydration and formed a densified zone at 28 and 90 days. This further increased the bond between coarse aggregates and the cement matrix. Hence, higher flexural and splitting tensile strengths were observed for both combined RCA concretes exceeding the values predicted based on AS3600 at 28 days.

The ultrasonic pulse velocity of combined RCA- 25 and RCA- 40 concretes at 7, 28, and 90 days are $3.25 \mathrm{~km} / \mathrm{s}, 3.75 \mathrm{~km} / \mathrm{s}, 3.95 \mathrm{~km} / \mathrm{s}$ and $3.30 \mathrm{~km} / \mathrm{s}, 3.85 \mathrm{~km} / \mathrm{s}, 4.15 \mathrm{~km} / \mathrm{s}$. Garbacz and Garboczi [69] reported that if ultrasonic pulse velocity of PC concrete falls between 3.5 and $4.5 \mathrm{~km} / \mathrm{s}$, that can be classified as good quality concrete free from large cracks and voids, which affect the structural reliability and durability in the long term. Due to the low density and high water absorption capacity of recycled 
aggregates, RCA concretes are expected to have slightly lower UPV values. Except at early age (7 days), the ultrasonic pulse velocity obtained for combined RCA concretes is in the good quality concrete range by 28 days, correlating with the less porous densified microstructure identified by the microscopy. This result is also in alignment with those reported in other RCA concrete literature $[40,70]$.

When density of concrete increases, the elastic modulus of concrete increases as well. This is due to a linear relationship between pore volume and the elastic modulus of concrete [71]. The packing density and porosity in concrete further determine the modulus of elasticity in concrete. Hence, a higher packing density would provide higher elastic modulus in concrete [72]. The low water absorption, dense C-S-H gel matrix, lack of micro-cracks in the ITZ and higher ultrasonic pulse velocity values at 28 days all indicate that the combined RCA concrete is free of large voids and cracks. This is hypothesised as the reason for the comparable elastic modulus evident in combined RCA concrete and the quarried aggregate concrete.
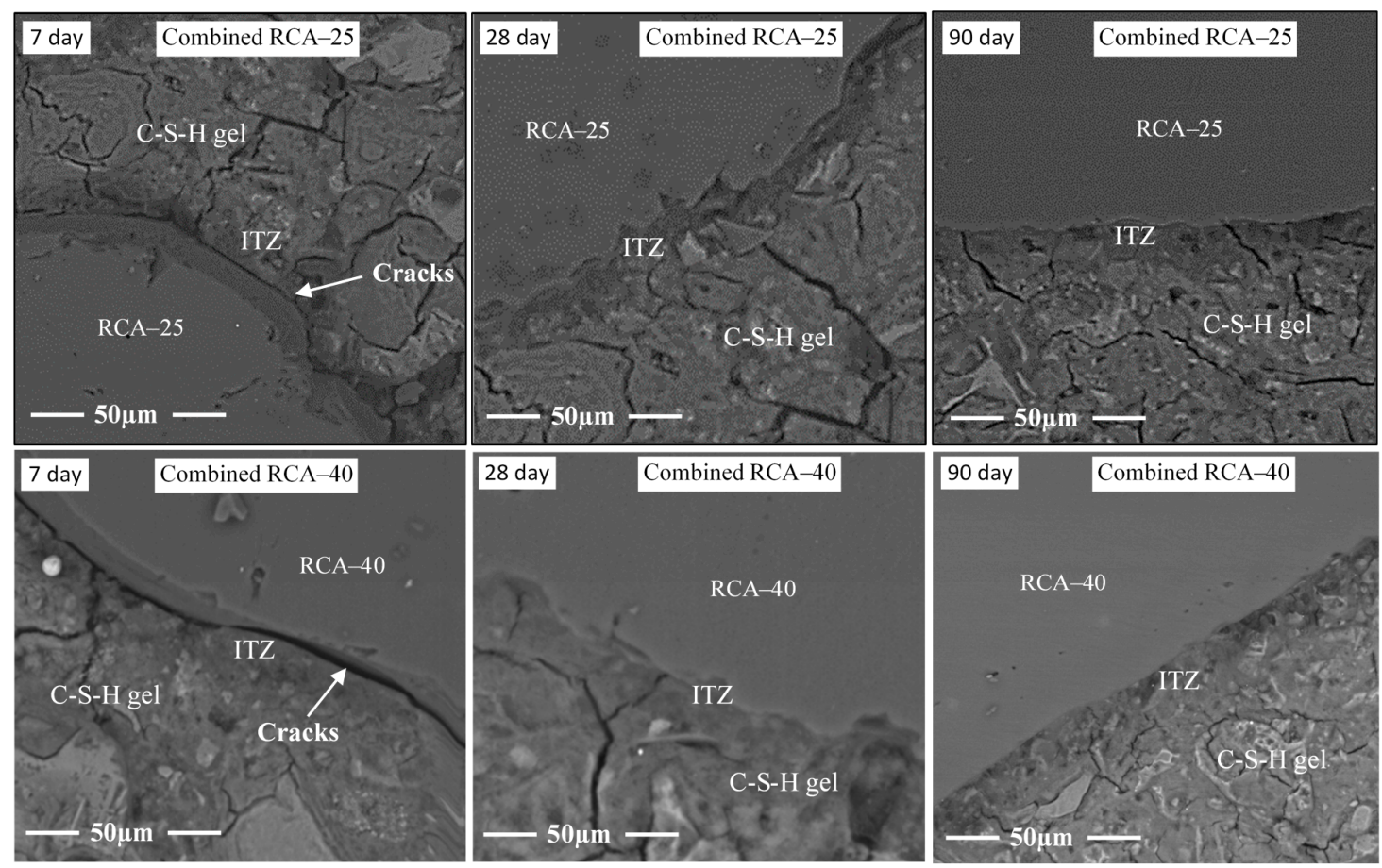

Figure 7. Microstructure development of Basalt aggregate and combined RCA concrete.

\subsection{Overview of Long Term Durability}

The compressive strength of the combined RCA concrete achieved the design strength of 25 and $40 \mathrm{MPa}$, satisfying the minimum compressive strength stated in AS3600 standard for the design of concrete structures in exposure classes A1/A2 and B1/B2, respectively. This designates that RCA concrete is a possible alternative to quarried aggregate concretes used at present. However, the protection of reinforcing steel in concrete due to ingress of water and aggressive agents determines the long term durability and service life of reinforced concrete [73]. It is the exposure to carbonation or chloride ingress that can destroy the primary protective passive layer in steel and result in the reinforcement corrosion. Due to lower water absorption observed in combined RCA concretes the use of the RCA is expected to minimize ingress of these aggressive agents into the RCA concrete, and provide higher resistance to chloride and sulfate attack. This is further supported by low shrinkage observed in combined RCA concrete as that reduces shrinkage deformation and micro-cracking. Formation of shrinkage cracking can lead to an increase of permeability to water and aggressive agents and deteriorate concrete through freeze-thaw in cold regions. Overall, the low water absorption coupled with low drying shrinkage in RCA concrete is expected to resist chlorides and sulfate ion attack. However, to determine this more clearly, long term corrosion and sulfate testing of RCA concrete is required. 


\section{Conclusions}

A systematic laboratory experimental investigation has been conducted to assess the feasibility of using manufactured RCA in concrete as an alternative for quarried coarse aggregate. The following conclusions can be drawn based on the material properties of RCA concrete:

- Compressive strength of combined RCA-25 and combined RCA-40 concretes increased from 19.29-44.50 MPa and 36.75-60.70 MPa from 7 to 90 days, respectively. This satisfied the specified 28-day design strength of exposure categories, A1/A2 (20/25 MPa) and B1/B2 (32/40 MPa) stated in Australian standards, AS3600.

- Aggregate grading of manufactured RCA matched with quarried aggregate increased the compressive strength of RCA concrete. This is due to aggregate packing density having a significant role in strength development.

- Both combined RCA-25 and combined RCA-40 concretes displayed comparable tensile strength and elastic modulus to an equivalent quarried coarse aggregate concrete of the same compressive strength. Experimentally observed flexural strength, splitting tensile strength, and elastic modulus are higher than the estimated values based on stated design equations in AS 3600, confirming that Australian standards can be used for the conservative design.

- Low water absorption coupled with high ultrasonic pulse velocity demonstrate that combined RCA concretes contain a dense microstructure and pore-structure free of large voids or cracks. This would be expected to prevent ingress of aggressive materials. The rough fracture surface of aggregate increased the bond between C-S-H gel matrix and RCA at ITZ.

- Combined RCA concretes display low drying shrinkage which is significantly lower than the maximum permitted value recommended by Australian standard.

Overall, this innovative and sustainable recycle product has significant potential as a coarse aggregate in concrete, with the substantial additional benefit of recycling wet concrete while minimizing environmental impact due to landfilling.

Author Contributions: Conceptualization, C.G.; Methodology, C.G. and D.W.L and S.S.; Software, C.G.; Data curation, C.G. and C.S.; Validation. C.G. and C.S.; Formal analysis, C.G. and C.S.; Investigation, C.G.; Writing-original draft, C.G.; Project administration, C.G.; Writing-review \& editing, C.S. and D.W.L and S.S.; Supervision, D.W.L. and S.S.; Funding acquisition, D.W.L. and S.S. All authors have read and agreed to the published version of the manuscript.

Funding: This research received no external funding.

Acknowledgments: The authors wish to acknowledge Cycrete Pty Ltd. for the supply of recycled coarse aggregates. The X-ray facility and Microscopy \& Microanalysis facility provided by RMIT University is also acknowledged. This research was conducted by the Australian Research Council Industrial Transformation Research Hub for nanoscience-based construction material manufacturing (IH150100006) and funded by the Australian Government.

Conflicts of Interest: The authors declare that they have no conflict of interest.

\section{References}

1. Sebaibi, N.; Boutouil, M. Reducing energy consumption of prefabricated building elements and lowering the environmental impact of concrete. Eng. Struct. 2020, 213, 110594. [CrossRef]

2. Hrabova, K.; Teply, B.; Vymazal, T. Sustainability assessment of concrete mixes. In Proceedings of the IOP Conference Series: Earth and Environmental Science, Ostrava, Czech Republic, 25-27 November 2019.

3. Neville, A.M. Properties of Concrete, 4th Ed. ed; Pearson Education Limited: Harlow, UK, 1996; Standards updated to 2002.

4. Bernhardt, D.; Reilly, J.F., II. Mineral Commodity Summaries (2019); US Geological Survey: Reston, VA, USA, 2019; Government Printing Office.

5. Cement Concrete \& Aggregates Australia. 2016. Available online: http://www.concrete.net.au/iMIS_Prod (accessed on 25 June 2020). 
6. Gunasekara, C.M. Influence of Properties of Fly Ash from Different Sources on the Mix Design and Performance of Geopolymer Concrete. Ph.D. Thesis, RMIT University, Melbourne, Australia, 2016.

7. Meyer, C. The greening of the concrete industry. Cem. Concr. Compos. 2009, 31, 601-605. [CrossRef]

8. Chen, C.; Habert, G.; Bouzidi, Y.; Jullien, A. Environmental impact of cement production: Detail of the different processes and cement plant variability evaluation. J. Clean. Prod. 2010, 18, 478-485. [CrossRef]

9. Peng, J.X.; Huang, L.; Zhao, Y.B.; Chen, P.; Zeng, L. Modeling of carbon dioxide measurement on cement plants. Adv. Mater. Res. 2013, 610, 2120-2128. [CrossRef]

10. Li, C.; Gong, X.Z.; Cui, S.P.; Wang, Z.H.; Zheng, Y.; Chi, B.C. $\mathrm{CO}_{2}$ emissions due to cement manufacture. Mater. Sci. Forum 2011, 685, 181-187. [CrossRef]

11. Huntzinger, D.N.; Eatmon, T.D. A life-cycle assessment of Portland cement manufacturing: Comparing the traditional process with alternative technologies. J. Clean. Prod. 2009, 17, 668-675. [CrossRef]

12. Dirgantara, R.; Gunasekara, C.; Law, D.W.; Molyneaux, T.K. Suitability of Brown Coal Fly Ash for Geopolymer Production. J. Mater. Civ. Eng. 2017, 29, 04017247. [CrossRef]

13. Nwakaire, C.M.; Yap, S.P.; Onn, C.C.; Yuen, C.W.; Ibrahim, H.A. Utilisation of recycled concrete aggregates for sustainable highway pavement applications; a review. Constr. Build. Mater. 2020, 235, 117444. [CrossRef]

14. Jiménez, L.F.; Domínguez, J.A.; Vega-Azamar, R.E. Carbon footprint of recycled aggregate concrete. Adv. Civ. Eng. 2018, 12. [CrossRef]

15. Khodr, M.; Law, D.W.; Gunasekara, C.; Setunge, S.; Brkljaca, R. Compressive strength and microstructure evolution of low calcium brown coal fly ash-based geopolymer. J. Sust. Cement-Based Mater. 2019, 9, 17-34. [CrossRef]

16. Tam, V.W.Y.; Soomro, M.; Evangelista, A.C.J. A review of recycled aggregate in concrete applications (2000-2017). Constr. Build. Mater. 2018, 172, 272-292. [CrossRef]

17. UNEP. Global Waste Management Outlook; UN: Osaka, Japan, 2016.

18. Service Contract on Management of Construction And Demolition Waste-SR1. Final Report Task 2, E.C.D. ENV, Editor. 2011, Bio Intelligence Service. p. 1-240. Available online: https://op.europa.eu/en/publicationdetail/-/publication/0c9ecefc-d07a-492e-a7e1-6d355b16dde4 (accessed on 24 June 2020).

19. Pickin, J.; Randell, P. Australian National Waste Report 2016. Available online: https://www.environment. gov.au/system/files/resources/d075c9bc-45b3-4ac0-a8f2-6494c7d1fa0d/files/national-waste-report-2016.pdf (accessed on 26 June 2020).

20. USEPA. Advancing Sustainable Materials Management: 2014 Fact Sheet; United States Environmental Protection Agency, Office of Land and Emergency Management: Washington, DC, USA, 2016.

21. Yang, H.; Xia, J.; Thompson, J.R.; Flower, R.J. Urban construction and demolition waste and landfill failure in Shenzhen, China. Waste Manag. 2017, 63, 393-396. [CrossRef] [PubMed]

22. Solid Waste and Hazardous Waste in Thailand; National Statistical Office: Bangkok, Thailand, 2012.

23. Baloyi, O.; Sehaswana, D.; Maringa, M.; Sibande, J.; Oelofse, S.; Schubert, M.; Swanepoel, H.; Godfrey, L.; Wakaba, L.; Muswema, A.; et al. National Waste Information Baseline Report; Department of Environmental Affairs of South Africa: Pretoria, South Africa, 2012.

24. Marzouk, M.; Azab, S. Environmental and economic impact assessment of construction and demolition waste disposal using system dynamics. Resour. Conserv. Recycl. 2014, 82, 41-49. [CrossRef]

25. Annual Review, European Aggregate Association (UEPG). 2015-2016. Available online: http://www.uepg. eu/uploads/Modules/Publications/uepg-ar2016-17_32pages_v04_small.pdf (accessed on 24 June 2020).

26. Evangelista, L.; de Brito, J. Mechanical behaviour of concrete made with fine recycled concrete aggregates. Cement Concrete Compos. 2007, 29,397-401. [CrossRef]

27. Pacheco-Torgal, F.; Ding, Y. Handbook of Recycled Concrete and Demolition Waste; Elsevier: Amsterdam, The Netherlands, 2013.

28. Rodríguez-Robles, D.; García-González, J.; Juan-Valdés, A.; Morán-del Pozo, J.M.; Guerra-Romero, M.I. Effect of mixed recycled aggregates on mechanical properties of recycled concrete. Mag. Concr. Res. 2015, 67, 247-256. [CrossRef]

29. Yang, J.; Du, Q.; Bao, Y. Concrete with recycled concrete aggregate and crushed clay bricks. Constr. Build. Mater. 2011, 25, 1935-1945. [CrossRef]

30. Martínez-Lage, I.; Martínez-Abella, F.; Vázquez-Herrero, C.; Pérez-Ordóñez, J.L. Properties of plain concrete made with mixed recycled coarse aggregate. Constr. Build. Mater. 2012, 37, 171-176. [CrossRef] 
31. Debieb, F.; Kenai, S. The use of coarse and fine crushed bricks as aggregate in concrete. Constr. Build. Mater. 2008, 22, 886-893. [CrossRef]

32. López-Uceda, A.; Ayuso, J.; López, M.; Jimenez, J.R.; Agrela, F.; Sierra, M.J. Properties of non-structural concrete made with mixed recycled aggregates and low cement content. Materials 2016, 9, 74. [CrossRef]

33. Silva, R.V.; De Brito, J.; Dhir, R.K. The influence of the use of recycled aggregates on the compressive strength of concrete: A review. Eur. J. Environ. Civ. Eng. 2015, 19, 825-849. [CrossRef]

34. Dhir, R.K.; Limbachiya, M.C.; Leelawat, T. BS 5328; BS 882. Suitability of recycled concrete aggregate for use in bs 5328 designated mixes. Proc. Inst. Civ. Eng. Struct. Build. 1999, 134, 257-274. [CrossRef]

35. Xiao, J.; Li, W.; Poon, C. Recent studies on mechanical properties of recycled aggregate concrete in China-A review. Sci. China Technol. Sci. 2012, 55, 1463-1480. [CrossRef]

36. Wang, H.L.; Wang, J.J.; Sun, X.Y.; Jin, W.L. Improving performance of recycled aggregate concrete with superfine pozzolanic powders. J. Cent. South Univ. 2013, 20, 3715-3722. [CrossRef]

37. Xie, J.; Huang, L.; Guo, Y.; Li, Z.; Fang, C.; Li, L.; Wang, J. Experimental study on the compressive and flexural behaviour of recycled aggregate concrete modified with silica fume and fibres. Constr. Build. Mater. 2018, 178, 612-623. [CrossRef]

38. Poon, C.; Kou, S. Effects of fly ash on mechanical properties of 10-year-old concrete prepared with recycled concrete aggregates. In Proceedings of the 2nd International Conference on Waste Engineering Management, ICWEM 2010, Shanghai, China, 13 October 2010; pp. 46-59.

39. Ferrari, G.; Miyamoto, M.; Ferrari, A. New sustainable technology for recycling returned concrete. Constr. Build. Mater. 2014, 67, 353-359. [CrossRef]

40. Kou, S.-C.; Zhan, B.-J.; Poon, C.-S. Feasibility study of using recycled fresh concrete waste as coarse aggregates in concrete. Constr. Build. Mater. 2011, 28, 549-556. [CrossRef]

41. Wang, R.; Zhang, Y.X. Recycling fresh concrete waste: A review. Struct. Concr. 2018, 19, 1939-1955. [CrossRef]

42. Kazaz, A.; Ulubeyli, S. Current Methods for the Utilization of the Fresh Concrete Waste Returned to Batching Plants. Proced. Eng. 2016, 161, 42-46. [CrossRef]

43. AS 3600 (2018) Concrete Structures, 3rd ed.; Australian Standard Limited: Sydney, Australia, 2018.

44. Thomas, D.; Hogan, M.; Shi, J. Manufactured Coarse Aggregate from Wet Concrete. International Publication No. WO 2017/132730; A1 World Intellectual Property Organization. 2017(PCT/AU2017/050086), 10 August 2017.

45. ASTM C150/C150M-18, in Standard Specification for Portland Cement; ASTM International: West Conshohocken, PA, USA, 2018.

46. AS 1141.21, Methods for Sampling and Testing Aggregates Aggregate Crushing Value; Standards Australia: Sydney, Australia, 1997; pp. 1-11.

47. VicRoads Standards RC 371.03, Test Method for Aggregate Impact Value; VicRoads: Melbourne, Australia, 2013.

48. AS 1141.23, Methods for Sampling and Testing Aggregates Los Angeles Value; Standards Australia Limited: Sydney, Australia, 2009.

49. AS 1141.4, Methods for Sampling and Testing Aggregates Bulk Density of Aggregate; Standards Australia Limited: Sydney, Australia, 2000; pp. 1-10.

50. ASTM C127, Standard Test Method for Relative Density (Specific Gravity) and Absorption of Coarse Aggregate; ASTM International: West Conshohocken, PA, USA, 2015.

51. VicRoads Standards RC 253.01. Determination of Aggregate Moisture Content and Estimated Free Water (Using Microwave or Hot Plate); VicRoads: Melbourne, Australia, 2013.

52. AS 1012.3.1:2014, Methods of Testing Concrete, Determination of Properties Related to the Consistency of Concrete-Slump Test; Standards Australia Limited: Sydney, Australia, 2014; p. 6.

53. AS 1012.12.2-1998 (R2014), Methods of Testing Concrete Determination of Mass Per Unit Volume of Hardened Concrete-Water Displacement Method; Standards Australia Limited: Sydney, Australia, 2014; p. 3.

54. AS 1012.9:2014, Methods of testing concrete Compressive strength tests-Concrete, mortar and grout specimens; Standards Australia Limited: Sydney, Australia, 2014; p. 11.

55. AS 1012.17-1997 (R2014), Methods of testing concrete Determination of the static chord modulus of elasticity and Poisson's ratio of concrete specimens; Standards Australia Limited: Sydney, Australia, 1997; p. 15.

56. AS 1012.21-1999 (R2014), Methods of testing concrete-Determination of water absorption and apparent volume of permeable voids in hardened concrete; Standards Australia Limited: Sydney, Australia, 1999. 
57. AS 1012.11-2000, Methods of testing concrete—Determination of the modulus of rupture; Standards Australia Limited: Sydney, Australia, 2000; pp. 1-5.

58. AS 1012.13:2015, Method 13: Determination of the Drying Shrinkage of Concrete for Samples Prepared in the Field or in the Laboratory, in Methods of Testing Concrete; Standards Australia Limited: Sydney, Australia, 2015.

59. AS 1012.8.1:2014, Methods of Testing Concrete Method for Making and Curing Concrete_Compression and Indirect Tensile Test Specimens; Standards Australia Limited: Sydney, Australia, 2014; p. 10.

60. ASTM C597, Standard Test Method for Pulse Velocity through Concrete; ASTM International: West Conshohocken, PA, USA, 2009.

61. Etxeberria, M.; Vázquez, E.; Marí, A.; Barra, M. Influence of amount of recycled coarse aggregates and production process on properties of recycled aggregate concrete. Cem. Concrete Res. 2007, 37, 735-742. [CrossRef]

62. AS 3600 (2009). Concrete Structures; Standards Australia Limited: Sydney, Australia, 2009; pp. 1-208.

63. Raphael, J.M. Tensile strength of concrete. Concrete Int. Mag. 1984, 81, 158-165.

64. Warner, R.F.; Rangan, B.V.; Hall, A.S. Reinforced Concrete; Addison Wesley Longman: Melbourne, Australia, 1998.

65. Kim, H.; Goulias, D.G. Shrinkage behavior of sustainable concrete with crushed returned concrete aggregate. J. Mater. Civ. Eng. 2015, 27, 04014204. [CrossRef]

66. Rendell, F.; Jauberthie, R.; Grantham, M. Deteriorated Concrete: Inspection and Physicochemical Analysis; Thomas Telford: London, UK, 2002.

67. VicRoads. Test Methods for the Assessment of Durability of Concrete; VicRoads: Melbourne, Australia, 2007.

68. Scrivener, K.L.; Crumbie, A.K.; Laugesen, P. The interfacial transition zone (ITZ) between cement paste and aggregate in concrete. Interface Sci. 2004, 12, 411-421. [CrossRef]

69. Garbacz, A.; Garboczi, E.J. Ultrasonic Evaluation Methods Applicable to Polymer Concrete Composites; US Department of Commerce, Technology Administration, National Institute of Standards and Technology: Gaithersburg, MD, USA, 2003.

70. Kou, S.-C.; Poon, C.-S. Effect of the quality of parent concrete on the properties of high performance recycled aggregate concrete. Constr. Build. Mater. 2015, 77, 501-508. [CrossRef]

71. Liu, M.Y.J.; Alengaram, U.J.; Jumaat, M.Z.; Mo, K.H. Evaluation of thermal conductivity, mechanical and transport properties of lightweight aggregate foamed geopolymer concrete. Energy Build. 2014, 72, 238-245. [CrossRef]

72. Puertas, F.; Palacios, M.; Manzano, H.; Dolado, J.S.; Rico, A.; Rodríguez, J. A model for the CASH gel formed in alkali-activated slag cements. J. Eur. Ceram. Soc. 2011, 31, 2043-2056. [CrossRef]

73. Broomfield, J.P. Corrosion of Steel in Concrete: Understanding, Investigation and Repair; CRC Press: Boca Raton, FL, USA, 2006.

(C) 2020 by the authors. Licensee MDPI, Basel, Switzerland. This article is an open access article distributed under the terms and conditions of the Creative Commons Attribution (CC BY) license (http://creativecommons.org/licenses/by/4.0/). 